\title{
ANALISIS KINERJA PROYEK "Y"MENGGUNAKAN METODE EARNED VALUE MANAGEMENT (Studi Kasus di PT Asian Sealand Engineering)
}

\author{
Elvi Wahyuni' ${ }^{1}$, Bambang Hendrawan ${ }^{2}$ )
}

1) Program Studi Administrasi Bisnis Politeknik Negeri Bengkalis,email: elviwahyuni09@gmail.com

2) Program Studi Administrasi Bisnis Politeknik Negeri Bengkalis,email: benk@polibatam.ac.id

\begin{abstract}
abtsract
PT Asia Sealand Engineering is a company engaged in offshore industry services. This study aims to profit. (EVM). The EVM concept of the three indicators is the Work Schedule Budget (BCWS), Work Performance Cost Budget (BCWP) and Actual Cost of Work Performance (ACWP). From these indicators are then analyzed to Cost Variance (CV), Cost Performance Index (CPI), Variance Schedule (SV) and Index Performance Schedule (SPI). After these talent indexes can be calculated Estimate at Completion $(E A C)$, Estimate to Complete (ETC) and Time Estimate (TE). The project under study is project "Y" module 301 train 3, bacth 5 with job specification in Structure section. The results show that the project cost overrun and sechedule overrun. This means focusing the project down. Estimated cost of project lit (ETC) is Rp. 710.980.113.00. Total total cost can be seen from the calculation of EAC is Rp. 7.595.984.113, - and the estimated time to generate TE is 302 days.
\end{abstract}

Keywords: Project Performance, Earned Value Management (EVM), Working Cost Budget (BCWS), Work Performance Cost (BCWP), Actual Cost of Work Cost (ACWP) Variance Cost (CV), Cost Performance Index (CPI) Schedule of Variance (SV), Index Performance Schedule (SPI) Estimate on Completion (EAC), Estimated to Complete (ETC) and Estimated Time (TE)

\footnotetext{
abstrak

PT Asian Sealand Engineering merupakan perusahaan yang bergerak dibidang jasa industri offshore. Penelitian ini bertujuan untuk menganalisa kinerja proyek berdasarkan waktu dan biaya menggunakan metode Earned Value Management (EVM).Konsep EVM terdiri dari tiga indikator yaitu Budget Cost of Work Schedule (BCWS), Budget Cost of Work Performance (BCWP) dan Actual Cost of Work Performance (ACWP). Dari ketiga indikator tersebut maka dilakukan analisis terhadap Cost Variance (CV), Cost Performance Index (CPI), Schedule Variance (SV) dan Schedule Performance Index (SPI). Setelah menghitung indeks-indeks tersebut maka dapat dihitung Estimate at Completion (EAC), Estimate to Complete (ETC) dan Time Estimate (TE). Adapun proyek yang diteliti adalah proyek "Y"modul 301 train 3, bacth 5 dengan spesifikasi pekerjaan di bagian Structure. Hasil penelitian menunjukan kinerja proyek mengalami cost overrun dan sechedule overrun. Ini berarti kinerja proyek mengalami penurunan. Estimasi biaya penyelesaian proyek (ETC) adalah Rp. 710.980.113,00. Total perkiraan biaya secara keseluruhan dapat dilihat dari perhitungan EAC yaitu Rp. 7.595.984.113,- dan estimasi waktu penyelesaian proyek TE adalah 302 hari.
}

Kata kunci : Kinerja Proyek, Earned Value Management (EVM), Budget Cost of Work Schedule (BCWS), Budget Cost of Work Performance (BCWP), Actual Cost of Work Performance (ACWP) Cost Variance $(C V)$, Cost Performance Index (CPI), Schedule Variance (SV), Schedule Performance Index (SPI) Estimate at Completion (EAC), Estimate to Complete (ETC) dan Time Estimate (TE) 


\section{PENDAHULUAN}

Batam merupakan lokasi yang strategis untuk berbagai industri terutama bidang Oil \& Gas. Banyaknya lahan yang dapat digunakan dan lokasi yang strategis membuat banyak pengusaha dan investor tertarik untuk membuat lahan bisnis di Batam. Kemajuan dalam kegiatan industri pada beberapa aspek memerlukan manajemen atau pengelolaan yang dituntut memiliki kinerja, kecermatan, keekonomisan, keterpaduan, kecepatan, ketepatan, ketelitian serta keamanan yang tinggi dalam rangka memperoleh hasil akhir yang sesuai dengan harapan. Pengelolaan suatu kegiatan dengan investasi skala besar dan tingkat kompleksitas yang sangat sulit membutuhkan cara teknis / metode yang teruji, sumber daya yang berkualitas, serta penerapan ilmu pengetahuan yang tepat dan update.

Kompleksnya pelaksanaan proyek selama pengerjaannya menyebabkan banyak proyek tidak berjalan sesuai dengan rencana. Baik dari segi waktu, biaya dan tenaga kerja. Untuk itu perlu dilakukan penilaian terhadap kinerja proyek agar dapat menjadi bahan acuan untuk pelaksanaan proyek yang akan datang.

\section{Identifikasi dan Perumusan Masalah}

Berdasarkan uraian di atas, maka penulis dapat merumuskan masalah yaitu bagaimana penerapan EVM (Earned Value Management) untuk menilai kinerja proyek Yamal LNG,

a. Bagaimana kinerja proyek berdasarkan perbedaan waktu pada perencanaan proyek dengan waktu aktual?

b. Bagaimana kinerja proyek berdasarkan biaya pada perencanaan proyek dengan biaya aktual ? c. Berapa estimasi biaya dan waktu yang dibutuhkan untuk menyelesaikan proyek?.

\section{Tujuan Penelitian}

Berdasarkan pada rumusan masalah yang telah dikemukakan, maka tujuan dilaksanakannya penelitian ini adalah untuk mengetahui bagaimana penerapan EVM (Earned Value Management) dalam menilai kinerja proyek Yamal LNG,

a. Untuk mengetahui apakah kinerja proyek berdasarkan waktu pelaksanaan proyek sesuai dengan rencana awal proyek

b. Untuk mengetahui apakah kinerja proyek berdasarkan biaya pelaksanaan proyek sesuai dengan rencana awal proyek

c. Untuk mengetahui estimasi biaya dan waktu yang dibutuhkan untuk menyelesaikan proyek.

\section{Manfaat Penelitian}

Dengan dilaksanakannya penelitian ini, diharapkan dapat memberi manfaat yang luas antara lain dapat memberikan informasi kepada pimpinan perusahaan akan penilaian kinerja proyek Yamal Lng, dan dapat menjadi bahan acuan atau informasi untuk proyek selanjutnya.

\section{KAJIAN TEORI}

\section{Kinerja Proyek}

Pengertian kinerja

Kinerja adalah gambaran mengenai tingkatan pencapaian pelaksanaan suatu kegiatan/ program/ kebijakan dalam mewujudkan sasaran, tujuan, misi dan visi organisasi yang tertuang dalam strategic planning suatu organisasi (Mahsun, 2009).

Pengukuran kinerja adalah suatu proses penilaian kemajuan pekerjaan 
Elvi \& Bambang, analisis kinerja proyek “ $y$ ”menggunakan metode earned value management ...

terhadap tujuan dan sasaran yang telah ditentukan sebelumnya termasuk informasi atas efisiensi penggunaan sumber daya dalam menghasilkan barang dan jasa, kualitas barang dan jasa, hasil kegiatan dibandingkan dengan maksud yang diinginkan dan efektivitas tindakan dalam mencapai tujuan (Robertson, 2002). Pengertian Proyek

Proyek adalah gabungan dari sumbersumber daya seperti manusia, material peralatan dan modal/biaya yang dihimpun dalam suatu wadah organisasi sementara untuk mencapai sasaran dan tujuan. (Husen, 2010)

Menurut Heryanto dan Triwibowo (2016) bentuk pengerjaan proyek dilakukan dengan dua cara yaitu:

- Swakelola

Pada intinya pengerjaan proyek swakelola adalah pengerjaan proyek yang dilakukan atau dikelola oleh organisasi atau perusahaan itu sendiri. Swakelola bukan berarti semua sumberdaya manusia yang terlibat di dalamnya adalah staf atau pegawai perusahaan tersebut. Bisa saja dengan menyewa tenaga ahli dalam kurun waktu tertentu (selama proyek berlangsung) untuk dijadikan sumberdaya personil proyek. Bisa juga SDM yang terlibat dalam pengerjaan adalah gabungan antara pegawai dan non pegawai (tenaga ahli yang disewa). Namun yang jelas pengelolaam atau manajemen proyek tersebut dlakukan oleh organisasi atau perusahaan yang bersangkutan.

- Sub-kontrak

Pengerjaan proyek secara sub-kontrak biasa disebut dengan singkatan proyek subkon, pada intinya adalah suatu proyek yang diproyekkan. Artinya bisa saja suatu organisasi atau perusahaan yang membuat atau juga bisa mendapatkan suatu proyek, namun proyek itu tidak dikerjakan sendiri, melainkan dilimpahkan ke pihak lain (perusahaan / konsultan lain) Bisa saja terjadi secara kontrak proyek yang dikerjakan adalah atas nama perusahaan $\mathrm{X}$, namun sebenarnya pelaksananya adalah perusahaan $\mathrm{Y}$. Dalam kasus seperti ini berarti perusahaan $\mathrm{X}$ melakukan sub-kontrak dengan perusahaan $\mathrm{Y}$.

Kinerja Proyek

Kinerja proyek dapat diukur dari indikator kinerja biaya, mutu, waktu serta keselamatan kerja dengan merencanakan dengan cermat, teliti, dan terpadu seluruh alokasi sumberdaya manusia, peralatan, material serta biaya yang sesuai dengan kebutuhan yang diperlukan. Semua itu diselaraskan dengan sasaran dengan tujuan proyek.

\section{Earned Value Mangement (EVM)}

Earned Value Management (EVM) adalah metodologi untuk mengukur dan mengkomunikasikan progress dari kinerja suatu proyek.Variabel penting dalam metodologi ini adalah waktu (schedule), biaya (cost) dan pekerjaan (work). Tujuan yang ingin dicapai dari metodologi ini adalah proyek yang efisien, yang berarti menyelesaikan pekerjaan dengan waktu yang telah ditentukan dengan meminimalisasi biaya atau materi yang dikeluarkan untuk proyek. Tujuan tersebut diharapkan dapat dicapai dengan cara mengevaluasi dan mengontrol resiko proyek dengan cara mengukur progress secara berkala (PMBOK Guide, 2013).

Dalam penentuan kinerja proyek dengan cara Earned Value atau Nilai Hasil, informasi yang ditampilkan berupa indikator dalam bentuk kuantitatif, yang menampilkan progress biaya dan jadwal proyek. Indikator ini menginformasikan posisi kemajuan proyek dalam jangka 
waktu tertentu serta dapat memperkirakan proyeksi kemajuan proyek pada periode selanjutnya. Indikator tersebut adalah sebagai berikut:

a) BCWS (Budgeted Cost of Work Schedule), menggambarkan anggaran rencana sampai pada periode tertentu terhadap volume rencana proyek yang akan dikerjakan.

b) BCWP (Budgeted Cost of Work Performed), menggambarkan anggaran rencana proyek pada periode tertentu terhadap apa yang telah dikerjakan pada volume pekerjaan aktual.

c) ACWP (Actual Cost of Work Performed) menggambarkan anggaran actual yang dihabiskan untuk pelaksanaan pekerjaan pada keadaaan volume pekerjaan aktual.

Dari ketiga indikator di atas, pengukuran kinerja biaya dan waktu untuk metode Earned Value menggunakan 3 jenis kurva $S$ sebagai nilai kumulatif biaya dengan fungsi waktu, yang terintegrasi dalam satu tampilan yang terdiri atas nilai kumulatif biaya: BCWS BCWP dan ACWP.

Kemudian dilakukan analisis terhadap penyimpangan yang terjadi pada biaya dan waktu / jadwal dengan cara mengukurnya, diuraikan di bawah ini.

Penyimpangan Jadwal / Waktu

a. SV (Schedule Variance $)=\mathrm{BCWP}-$ BCWS

$\mathrm{SV}>0$, progress actual > rencana: terjadi percepatan proyek terhadap rencana (schedule underrun)

$\mathrm{SV}<0, \quad$ progress actual $<$ rencana:terjadi keterlambatan proyek terhadap rencana (schedule overrun)

b. SPI (Schedule Performance Index) $=$ BCWP / BCWS
SPI > 1, progress actual > rencana: terjadi percepatan proyek terhadap rencana (schedule underrun)

SPI < 1, progress actual <rencana: terjadi kerterlambatan proyek terhadap rencana (schedule overrun)

Penyimpangan Biaya

a. $\mathrm{CV}$ (Cost Variance $)=\mathrm{BCWP}-$ ACWP

$\mathrm{CV}>0$, biaya volume aktual $>$ biaya actual (cost underrun)

$\mathrm{CV}<0$, biaya volume aktual $<$ biaya actual (cost overrun)

b. CPI (Cost Performance Index) = BCWP / ACWP

$\mathrm{CPI}>1$, biaya volume aktual

$>$ biaya aktual (cost underrun)

CPI $<1$, biaya volume aktual

$<$ biaya aktual (cost overrun)

Dengan menghitung indeks-indeks seperti di atas akan terlihat bahwa proyek akan terlambat atau lebih cepat dan biaya yang harus dikeluarkan akan berlebih atau kurang dari yang dianggarkan.

Perkiraan Biaya dan waktu Penyelesaian Akhir Proyek

Estimate at Completion merupakan perkiraan total biaya proyek,

$\mathrm{EAC}=\mathrm{ACWP}+\mathrm{ETC}$

Estimate to Complete merupakan perkiraan biaya untuk pekerjaan tersisa.

Untuk progress fisik $<50 \%$

$\mathrm{ETC}=$ Ang- BCWP

Untuk progress fisik $>50 \%$

$\mathrm{ETC}=(\mathrm{Ang}-\mathrm{BCWP}) / \mathrm{CPI}$

Time Estimate merupakan waktu penyelesaian proyek,

$\mathrm{TE}==\mathrm{ATE}+(\underline{\text { OD- (ATE } \times \mathrm{SPI})})$ SPI

ATE adalah waktu yang ditempuh dan OD adalah waktu yang direncanakan.

Analisa Perkiraan Rencana Terhadap Penyelesaian Proyek 
Elvi \& Bambang, analisis kinerja proyek “ $y$ ”menggunakan metode earned value management ...

\section{Kerangka Pemikiran}

Menurut Sekaran dalam Sugiyono (2015) bahwa, kerangka pemikiran model konseptual tentang bagaimana teori berhubungan dengan berbagai faktor yang telah diidentifikasikan sebagai masalah yang penting.

Kerangka pemikiran tersebut adalah sebagai berikut:

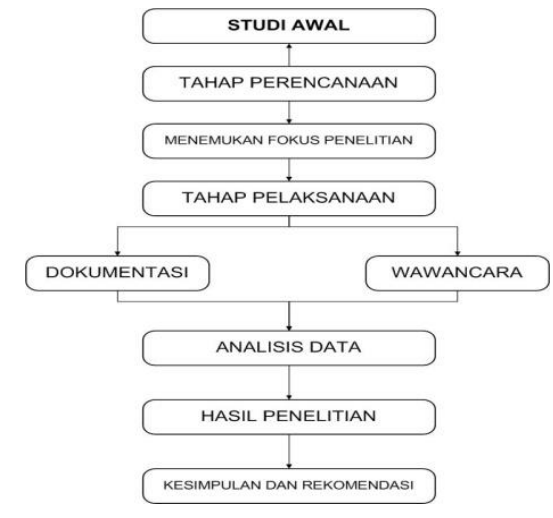

Gambar : Kerangka Pemikiran

\section{METODE PENELITIAN}

\section{Desain atau Rancangan Penelitian}

Metode yang digunakan dalam penelitian ini adalah metode deskriptif kuantitatif dengan model studi kasus. Penelitian kualitatif adalah metode penelitian yang berlandaskan pada filsafat postpositivisme, digunakan untuk meneliti pada kondisi objek yang alamiah dengan peneliti sebagai instrument kunci, teknik pengumpulan datanya dilakukan secara triangulasi, analisis datanya bersifat induktif dan hasil penelitian kualitatif lebih menekan makna daripada generalisasi (Sugiyono, 2008).

\section{Objek dan Ruang Lingkup Penelitian}

Objek penelitian dalam penulisan ini adalah salah satu Proyek "Y"di kawasan industri Batu Ampar yang dikerjakan oleh PT Asian Sealand Engineering. Metode pengumpulan data yang akan dilakukan adalah survey ke lokasi lansung dan interview yaitu pengumpulan data primer dan data sekunder, data melalui wawancara lansung dengan Proyek Manajer, Engineer dan karyawan yang terlibat lansung dengan Proyek Yamal LNG, meminta data gambar dan beberapa data tentang proyek Yamal LNG, jadwal kerja, biaya dan proses erection untuk menganalisa penelitian yang akan dilakukan.

\section{Jenis dan Sumber Data}

Adapun jenis data yang digunakan dalam penelitian ini adalah sebagai berikut:

a. Data primer merupakan data yang diperoleh penelitian secara langsung dari responden dengan mewawancarai project manager, project engineer, dan planner yang berkaitan dengan proyek Yamal LNG.

b. Data sekunder yaitu data yang diperoleh nelalui studi dokumentasi dengan mempelajari berbagai tulisan melalui buku, jurnal, majalah, dan sumbersumber lain yang mendukung penelitian ini.

\section{Teknik Pengumpulan Data}

Teknik penelitian yang digunakan untuk memperoleh data adalah sebagai berikut:

a. Observasi adalah mengamati atau meninjau secara langsung kegiatankegiatan di lapangan yang berhubungan dengan topik pembahasan.

b. Wawancara adalah proses memperoleh keterangan untuk tujuan penelitian dengan cara tanya jawab sambil bertatap muka antara penanya untuk memperoleh data yang diperlukan. Tanya jawab ini dilakukan oleh peneliti dengan pihak responden tentang hasil jawaban responden di daftar pertanyaan.

c. Dokumentasi adalah metode pengumpulan data yang datanya diperoleh dari buku, internet atau 
dokumen lain yang menunjang penelitian yang dilakukan.

\section{Teknik Analisis Data}

Teknik analisis data menggunakan rumus Earned Value Management (EVM), adapun rumusnya adalah sebagai berikut:

a. Menghitung penyimpangan waktu pelaksanaan proyek yaitu menghitung selisih antara waktu perencanaan proyek dengan waktu aktual pelaksanaan proyek.

- SV (Schedule Variance) $=$ BCWP BCWS

$\mathrm{SV}>0$, progress actual > rencana: terjadi percepatan proyek terhadap rencana (schedule underrun)

$\mathrm{SV}<0$, progress actual < rencana: terjadi keterlambatan proyek terhadap rencana (schedule overrun)

- $\quad$ SPI (Schedule Performance Index $)=$ BCWP / BCWS

SPI > 1, progress actual > rencana: terjadi percepatan proyek terhadap rencana (schedule underrun)

SPI < 1, progress actual < rencana: terjadi kerterlambatan proyek terhadap rencana (schedule overrun)

b. Menghitung penyimpangan biaya pelaksanaan proyek yaitu menghitung selisih antara biaya perencanaan proyek dengan biaya aktual pelaksanaan proyek.

- $\mathrm{CV}$ (Cost Variance) = BCWP ACWP

$\mathrm{CV}>0$, biaya volume aktual > biaya actual (cost underrun)

$\mathrm{CV}<0$, biaya volume aktual < biaya actual (cost overrun)

- CPI (Cost Performance Index) = BCWP / ACWP

CPI > 1, biaya volume aktual > biaya aktual (cost underrun)

CPI < 1 , biaya volume aktual < biaya aktual (cost overrun)

c. Menghitung estimasi waktu penyelesaian proyek yaitu menghitung perkiraan waktu yang dibutuhkan untuk menyelesaikan proyek.
- Estimate at Completion merupakan perkiraan total biaya proyek, $\mathrm{EAC}=\mathrm{ACWP}+\mathrm{ETC}$

- Estimate to Complete merupakan perkiraan biaya untuk pekerjaan tersisa.

Untuk progress fisik $<50 \%$

$\mathrm{ETC}=$ Ang- BCWP

Untuk progress fisik $>50 \%$

$\mathrm{ETC}=($ Ang $-\mathrm{BCWP}) / \mathrm{CPI}$

- Time Estimate merupakan waktu penyelesaian proyek, $\mathrm{TE}=\mathrm{ATE}+(\mathrm{OD}-(\mathrm{ATE} \times \mathrm{SPI})$ )

SPI

\section{HASIL PENELITIAN}

Proyek dalam penelitian ini adalah salah satu proyek "Y"yaitu modul 301, train 3 , bacth 5 dengan spesifikasi pekerjaan di bagian Structure. Berlokasi di kawasan Industri Batu Ampar, Batam. Bentuk pengerjaan proyek adalah sub-kontrak yaitu proyek yang diproyekkan. Ada beberapa bagian dalam penyelesaian proyek di antaranya, structre, piping, blasting \& painting dan electrica \& instrument. Dalam hal ini PT Asian Sealand Engineering hanya mengerjakan bagian structure.

Berikut adalah gambaran tentang pelaksanaan pekerjaan proyek modul 301 bagian structure: 
Elvi \& Bambang, analisis kinerja proyek “y”menggunakan metode earned value management...

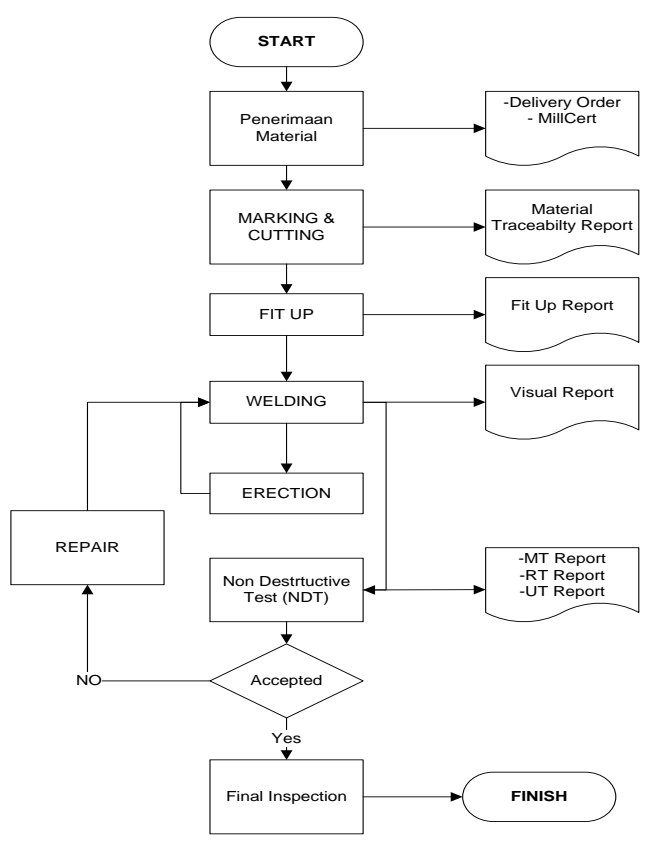

Gambar : Skema Pekerjaan Proyek

Keterangan:

1. Proses penerimaan material harus dilengkapi dengan dokumen Delivery Order dan Mill Cert (sertifikat material) dari vendor.

2. Setelah material diterima maka dilakukan proses marking \& cutting oleh fitter. Setelah itu Inspector melakukan inspeksi terhadap material yang sudah dipotong apakah sesuai atau tidak. Kemudian Document Control menyiapkan Material Traceability Report.

3. Setelah itu dilakukan proses fit up, dalam proses ini juga dilakukan proses dimensional control agar dimensi material yang disambung sesuai dengan drawing. Setelah itu dilakukan proses welding, biasanya menggunakan jenis tug weld, yaitu pengelasan sementara agar material dapat tersambung dalam proses ini, hasil welding tidak perlu dilakukan Non Destructive Test (NDT).

4. Setelah itu maka dilakukan proses erection yaitu penyambungan antar blok. Untuk proses penyambungan antar blok ini juga dilakukan proses welding oleh welder. Ada banyak jenis welding yang digunakan, tergantung dengan drawing yang ada. Untuk setiap proses welding inspector melakukan check visual dan document control menyiapkan visual report sesuai request dari Inspector. Untuk setiap proses inspeksi document control juga harus menyiapkan dokumen Request for Inspection (RFI).

5. Proses NDT dilakukan untuk memeriksa hasil welding apakah ada kerusakan atau tidak. Dalam proses ini ada 3 jenis proses NDT yang dilakukan yaitu Magnet Particle Testing (MT), Ultrasonic Testing (UT), Radiographic Testing (RT). Document control harus menyiapkan report untuk masingmasing test. Jika hasil welding dapat diterima maka bisa dilanjutkan ke proses selanjutnya. Jika ada kerusakan yang tidak dapat ditoleransi maka dilakukan repair.

6. Setelah semua proses selesai maka dilakukan final inspection bersama client, inspeksi ini untuk memastikan kembali semua sudah terinspeksi dengan baik.

7. Progress pekerjaan diakui setelah semua proses dilakukan dan setiap dokumen dari setiap proses pekerjaan di approve oleh main contractor.

Untuk proses klaim ke main contractor, perusahaan sebagai sub contractor harus menyiapkan data base yang terdiri dari keseluruhan report dari setiap proses pekerjaan. Data base ini adalah Welding Traceabilty Report (WTR).

Perhitungan analisis Earned Value Mangement menggunakan hitungan Microsoft excel. PV (Planned Value) dan EV (Earned Value) dihitung menggunakan data dari laporan bulanan. Pembangunan structure proyek "Y" dilaksanakan dalam kurun waktu 8 bulan dengan perhitungan 26 
hari masa kerja setiap bulannya dan nilai kontrak sebesar Rp. 5.940.000.000,00. Aktual pengerjaan proyek sekarang sudah berjalan 11 bulan dan telah menghabiskan dana sebesar Rp. 6.855.000.000,00.

Rincian rencana biaya dan waktu serta biaya dan waktu aktual proyek dapat dilihat dari tabel berikut:

Tabel 1 : Tabel Rincian Bobot Rencana dan Pekerjaan Proyek

\begin{tabular}{|c|c|c|c|}
\hline Train & \multicolumn{3}{|l|}{3} \\
\hline Batch & \multicolumn{3}{|l|}{5} \\
\hline Module & \multicolumn{3}{|c|}{ ESS-301 (Yamal Lng) } \\
\hline Company & \multicolumn{3}{|c|}{ Asian Sealand Engineering Pte. Ltd } \\
\hline $\mathrm{Job}$ & \multicolumn{3}{|l|}{ STRUCTURE } \\
\hline Budget plan & \multicolumn{3}{|l|}{ Rp5,940,000,000 } \\
\hline Time plan & \multicolumn{3}{|c|}{8 month (208 days) } \\
\hline Actual Cost & \multicolumn{3}{|c|}{ Rp6,885,000,000.00 } \\
\hline Actual Time & \multicolumn{3}{|c|}{11 month (286 days) } \\
\hline Month & $\begin{array}{c}\% \text { Progress } \\
\text { Plan }\end{array}$ & $\begin{array}{l}\% \text { Actual } \\
\text { Progress }\end{array}$ & Actual Cost/ Month \\
\hline 1 & $10.00 \%$ & $10.00 \%$ & Rp525,000,000.00 \\
\hline 2 & $20.00 \%$ & $21.50 \%$ & $\mathrm{Rp} 1,140,000,000.00$ \\
\hline 3 & $35.00 \%$ & $34.00 \%$ & $\mathrm{Rp} 2,340,900,000.00$ \\
\hline 4 & $50.00 \%$ & $44.60 \%$ & $\mathrm{Rp} 3,070,000,000.00$ \\
\hline 5 & $65.00 \%$ & $48.00 \%$ & $\mathrm{Rp} 2,904,800,000.00$ \\
\hline 6 & $80.00 \%$ & $53.30 \%$ & $\mathrm{Rp} 3,000,705,000.00$ \\
\hline 7 & $90.00 \%$ & $60.00 \%$ & $\mathrm{Rp} 4,000,000,000.00$ \\
\hline 8 & $100.00 \%$ & $69.00 \%$ & $\mathrm{Rp} 4,250,650,000.00$ \\
\hline 9 & & $78.00 \%$ & $\mathrm{Rp} 5,000,300,000.00$ \\
\hline 10 & & $85.00 \%$ & Rp5,852,250,000.00 \\
\hline 11 & & $90.64 \%$ & Rp6,885,000,000.00 \\
\hline
\end{tabular}

Dari tabel 1 dapat disimpulkan bahwa waktu dan biaya pengerjaan proyek sudah melebihi dari jadwal dan anggaran yang sudah direncanakan. Proyek sudah mengalami keterlambatan selama 3 bulan dan selisih biaya aktual dengan anggaran sebanyak Rp. 945.000.000,00. Pada bulan akhir pekerjaan proyek yaitu bulan ke 11, 
Elvi \& Bambang, analisis kinerja proyek “ $y$ ”menggunakan metode earned value management ...

proyek masih memiliki 9,36 \% bobot pekerjaan yang harus di selesaikan.

Berikut adalah chart perbandingan antara progress plan dengan actual progress:

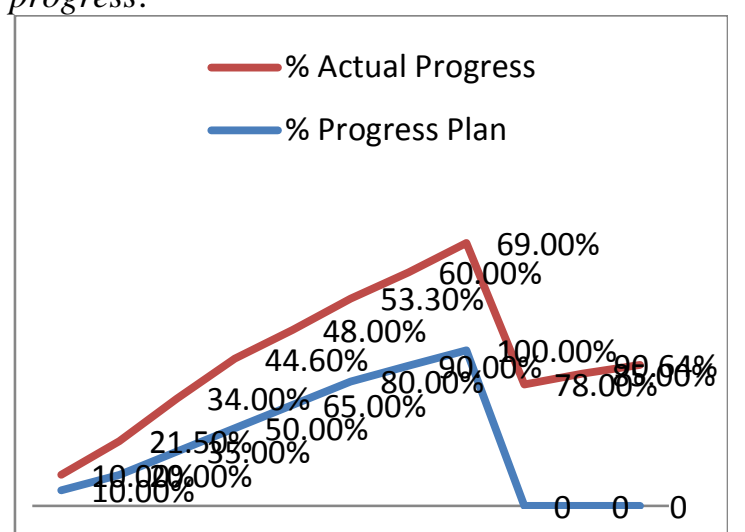

$\begin{array}{lllllllllll}1 & 2 & 3 & 4 & 5 & 6 & 7 & 8 & 9 & 10 & 11\end{array}$

Grafik : Grafik Perbandingan Progress Plan dengan Actual Progress

\section{Budget Cost Of Work Schedule (BCWS)}

Budget Cost of Work Schedule (BCWS) adalah biaya / anggaran yang direncanakan untuk menyelesaikan suatu pekerjaan. Planned Value (PV) adalah biaya yang dianggarkan dari pekerjaan proyek berdasarkan anggaran dan bobot rencana pelaksanaan proyek.

Contoh perhitungan BCWS pada bulan ke 1 adalah sebagai berikut:

$\%$ bobot rencana pada bulan ke $1=10 \%$

Nilai kontrak proyek $=$

Rp. 5.940.000.000,00

Jadi:

$\mathrm{BCWS}=(\%$ Perencanaan $) \times($ Anggaran $)$

$$
\begin{aligned}
& =10 \% \times \text { Rp. } 5.940 .000 .000,00 \\
& =\text { Rp. } 594.000 .000,00
\end{aligned}
$$

Besarnya BCWS tiap bulan dapat dilihat pada tabel berikut:

\begin{tabular}{|c|c|c|c|c|c|}
\hline \multirow[b]{2}{*}{$\begin{array}{c}\text { Bulan } \\
\text { ke }\end{array}$} & \multirow[b]{2}{*}{$\begin{array}{c}\text { Nilai Kontrak/ } \\
\text { Anggaran }\end{array}$} & \multicolumn{4}{|c|}{ Budget Cost Of Work Schedule (BCWS) } \\
\hline & & $\begin{array}{c}\% \\
\text { Perencanaan } \\
\text { Pekerjaan }\end{array}$ & $\begin{array}{c}\% \text { Bobot } \\
\text { Pekerjaan }\end{array}$ & $\begin{array}{c}\text { Planned Value } \\
\text { (PV) }\end{array}$ & $\begin{array}{l}\text { PV Komulatif/ } \\
\text { BCWS }\end{array}$ \\
\hline 1 & Rp5,940,000,000 & $10.00 \%$ & $10.00 \%$ & Rp594,000,000 & Rp594,000,000 \\
\hline 2 & Rp5,940,000,000 & $20.00 \%$ & $10.00 \%$ & Rp594,000,000 & Rp1,188,000,000 \\
\hline 3 & Rp5,940,000,000 & $35.00 \%$ & $15.00 \%$ & Rp891,000,000 & $\mathrm{Rp} 2,079,000,000$ \\
\hline 4 & Rp5,940,000,000 & $50.00 \%$ & $15.00 \%$ & Rp891,000,000 & $\mathrm{Rp} 2,970,000,000$ \\
\hline 5 & Rp5,940,000,000 & $65.00 \%$ & $15.00 \%$ & Rp891,000,000 & Rp3,861,000,000 \\
\hline 6 & Rp5,940,000,000 & $80.00 \%$ & $15.00 \%$ & Rp891,000,000 & Rp4,752,000,000 \\
\hline 7 & Rp5,940,000,000 & $90.00 \%$ & $10.00 \%$ & Rp594,000,000 & Rp5,346,000,000 \\
\hline 8 & Rp5,940,000,000 & $100.00 \%$ & $10.00 \%$ & Rp594,000,000 & Rp5,940,000,000 \\
\hline
\end{tabular}

Tabel 2: Budget Cost Of Work Schedule (BCWS)

Budget Cost of Work Performance (BCWP) adalah jumlah nilai hasil pekerjaan yang telah diselesaikan untuk kurun waktu tertentu, didapat dari laporan bulanan. Nilai hasil (Earned Value) adalah biaya yang diselesaikan oleh pelaksanaan berdasarkan anggaran dan aktual pelaksanaan proyek.

Contoh perhitungan BCWP pada bulan

ke 1 adalah sebagai berikut:

$\%$ bobot pelaksanaan pada bulan ke $1=10 \%$ 
Nilai kontrak proyek $=$

Rp. $5.940 .000 .000,00$

Jadi:

$\mathrm{BCWP}=\%$ Penyelesaiaan $\mathrm{x}$ Anggaran
$=10 \% \times$ Rp. $5.940 .000 .000,00$

$=$ Rp. 594.000.000,00.

Besarnya BCWP pada tiap bulan dapat dilihat pada tabel berikut:

\begin{tabular}{|c|c|c|c|c|c|}
\hline \multirow{2}{*}{$\begin{array}{c}\text { Bulan } \\
\text { ke }\end{array}$} & $\begin{array}{c}\text { Nilai Kontrak } \\
\text { /Anggaran }\end{array}$ & \begin{tabular}{c} 
Pelaksana \\
an \\
\cline { 3 - 6 }
\end{tabular} & $\begin{array}{c}\text { Pekerjaa } \\
\text { n Bobot } \\
\text { Pekerjaa } \\
\mathbf{n}\end{array}$ & $\begin{array}{c}\text { Earned Value } \\
\text { (EV) }\end{array}$ & $\begin{array}{c}\text { EV Komulatif/ } \\
\text { BCWP }\end{array}$ \\
\hline 1 & $\mathrm{Rp} 5,940,000,000$ & $10.00 \%$ & $10.00 \%$ & $\mathrm{Rp} 594,000,000$ & $\mathrm{Rp594,000,000}$ \\
\hline 2 & $\mathrm{Rp} 5,940,000,000$ & $21.50 \%$ & $11.50 \%$ & $\mathrm{Rp} 1,277,100,000$ & $\mathrm{Rp} 1,277,100,000$ \\
\hline 3 & $\mathrm{Rp} 5,940,000,000$ & $34.00 \%$ & $12.50 \%$ & $\mathrm{Rp} 2,019,600,000$ & $\mathrm{Rp} 2,019,600,000$ \\
\hline 4 & $\mathrm{Rp} 5,940,000,000$ & $44.60 \%$ & $10.60 \%$ & $\mathrm{Rp} 2,649,240,000$ & $\mathrm{Rp} 2,649,240,000$ \\
\hline 5 & $\mathrm{Rp} 5,940,000,000$ & $48.00 \%$ & $3.40 \%$ & $\mathrm{Rp} 2,851,200,000$ & $\mathrm{Rp} 2,851,200,000$ \\
\hline 6 & $\mathrm{Rp} 5,940,000,000$ & $53.30 \%$ & $5.30 \%$ & $\mathrm{Rp} 3,166,020,000$ & $\mathrm{Rp} 3,166,020,000$ \\
\hline 7 & $\mathrm{Rp} 5,940,000,000$ & $60.00 \%$ & $6.70 \%$ & $\mathrm{Rp} 3,564,000,000$ & $\mathrm{Rp} 3,564,000,000$ \\
\hline 8 & $\mathrm{Rp} 5,940,000,000$ & $69.00 \%$ & $9.00 \%$ & $\mathrm{Rp} 4,098,600,000$ & $\mathrm{Rp} 4,098,600,000$ \\
\hline 9 & $\mathrm{Rp} 5,940,000,000$ & $78.00 \%$ & $9.00 \%$ & $\mathrm{Rp} 4,633,200,000$ & $\mathrm{Rp} 4,633,200,000$ \\
\hline 10 & $\mathrm{Rp} 5,940,000,000$ & $85.00 \%$ & $7.00 \%$ & $\mathrm{Rp} 5,049,000,000$ & $\mathrm{Rp} 5,049,000,000$ \\
\hline 11 & $\mathrm{Rp} 5,940,000,000$ & $90.64 \%$ & $5.64 \%$ & $\mathrm{Rp} 5,384,016,000$ & $\mathrm{Rp} 5,384,016,000$ \\
\hline
\end{tabular}

Tabel: Budget Cost Of Work Performance (BCWP)

\section{Schedule Variance (SV)}

Schedule Variance (SV) merupakan selisih dari besarnya Budget Cost of Work Performance (BCWP) dengan Budget Cost of Work Schedule (BCWS) .

Schedule Variance $(\mathrm{SV})=\mathrm{BCWP}-\mathrm{BCWS}$ Dengan ketentuan jika:

- $\quad \mathrm{SV}>0$, progress actual > rencana: terjadi percepatan proyek terhadap rencana (schedule underrun)

- $\quad \mathrm{SV}<0$, progress actual <rencana : terjadi keterlambatan proyek terhadap rencana (schedule overrun).

Contoh perhitungan SV pada bulan ke 1 adalah sebagai berikut:
Nilai BCWP bulan ke $1=$

Rp.594.000.000,00

Nilai BCWS bulan ke $1=$

Rp.594.000.000,00

Jadi:

SV = BCWP - BCWS

$=$ Rp.594.000.000 - Rp.594.000.000

$=0$

Hasil perhitungan pada bulan ke 1 menunjukan angka 0 , sehingga dapat disimpulkan bahwa proyek berjalan sesuai rencana, tidak mengalami kecepatan atau keterlambatan.

Besarnya SV tiap bulan dapat dilihat pada tabel berikut : 
Elvi \& Bambang, analisis kinerja proyek “y”menggunakan metode earned value management ...

\begin{tabular}{|c|r|r|r|l|}
\hline $\begin{array}{c}\text { Bulan } \\
\text { ke }\end{array}$ & PV Komulatif & EV Komulatif & $\begin{array}{r}\text { Schedule Variance } \\
\text { (SV) }\end{array}$ & \multicolumn{1}{|c|}{ Keterangan } \\
\hline 1 & $\mathrm{Rp} 594,000,000$ & $\mathrm{Rp} 594,000,000$ & $\mathrm{Rp} 0$ & schedule on time \\
\hline 2 & $\mathrm{Rp} 1,188,000,000$ & $\mathrm{Rp} 1,277,100,000$ & $\mathrm{Rp} 89,100,000$ & schedule underrun \\
\hline 3 & $\mathrm{Rp} 2,079,000,000$ & $\mathrm{Rp} 2,019,600,000$ & $-\mathrm{Rp} 59,400,000$ & schedule overrun \\
\hline 4 & $\mathrm{Rp} 2,970,000,000$ & $\mathrm{Rp} 2,649,240,000$ & $-\mathrm{Rp} 320,760,000$ & schedule overrun \\
\hline 5 & $\mathrm{Rp} 3,861,000,000$ & $\mathrm{Rp} 2,851,200,000$ & $-\mathrm{Rp} 1,009,800,000$ & schedule overrun \\
\hline 6 & $\mathrm{Rp} 4,752,000,000$ & $\mathrm{Rp} 3,166,020,000$ & $-\mathrm{Rp} 1,585,980,000$ & schedule overrun \\
\hline 7 & $\mathrm{Rp} 5,346,000,000$ & $\mathrm{Rp} 3,564,000,000$ & $-\mathrm{Rp} 1,782,000,000$ & schedule overrun \\
\hline 8 & $\mathrm{Rp} 5,940,000,000$ & $\mathrm{Rp} 4,098,600,000$ & $-\mathrm{Rp} 1,841,400,000$ & schedule overrun \\
\hline
\end{tabular}

Tabel : Schedule Variance (CV)

\section{Schedule Performance Indeks (SPI)}

Schedule Performance Index (SPI) menggambarkan seberapa efektif proses aktual di lapangan dengan perencanaan proyek.

Schedule Performance Index (SPI) = BCWP / BCWS

Dengan ketentuan jika:

- SPI > 1, progress actual> rencana: terjadi percepatan proyek terhadap rencana (schedule underrun)

- SPI < 1, progress actual< rencana: terjadi kerterlambatan proyek terhadap rencana (schedule overrun)

\begin{tabular}{|c|r|r|r|l|}
\hline $\begin{array}{c}\text { Bulan } \\
\text { ke }\end{array}$ & PV Komulatif & EV Komulatif & (SPI) & \multicolumn{1}{|c|}{ Keterangan } \\
\hline 1 & $\mathrm{Rp} 594,000,000$ & $\mathrm{Rp} 594,000,000$ & 1.00 & schedule On time \\
\hline 2 & $\mathrm{Rp} 1,188,000,000$ & $\mathrm{Rp} 1,277,100,000$ & 1.08 & schedule underrun \\
\hline 3 & $\mathrm{Rp} 2,079,000,000$ & $\mathrm{Rp} 2,019,600,000$ & 0.97 & schedule overrun \\
\hline 4 & $\mathrm{Rp} 2,970,000,000$ & $\mathrm{Rp} 2,649,240,000$ & 0.89 & schedule overrun \\
\hline 5 & $\mathrm{Rp} 3,861,000,000$ & $\mathrm{Rp} 2,851,200,000$ & 0.74 & schedule overrun \\
\hline 6 & $\mathrm{Rp} 4,752,000,000$ & $\mathrm{Rp} 3,166,020,000$ & 0.67 & schedule overrun \\
\hline 7 & $\mathrm{Rp} 5,346,000,000$ & $\mathrm{Rp} 3,564,000,000$ & 0.67 & schedule overrun \\
\hline 8 & $\mathrm{Rp} 5,940,000,000$ & $\mathrm{Rp} 4,098,600,000$ & 0.69 & schedule overrun \\
\hline
\end{tabular}

Contoh perhitungan SPI pada bulan ke 1 adalah sebagai berikut:

Nilai BCWP bulan ke $1=$ Rp.594.000.000,00

Nilai BCWS bulan ke $1=$ Rp.594.000.000,00

Jadi:

SPI $=$ BCWP/BCWS

$=594.000 .000 / 594.000 .000$

$=1$

Besarnya SPI tiap bulan dapat dilihat dari tabel berikut:

Tabel : Schedule Performance Index (SPI) 


\section{Cost Variance (CV)}

Cost Variance (CV) menggambarkan selisih antara biaya volume aktual dengan biaya aktual.

Cost Variance $(\mathrm{CV})=\mathrm{BCWP}-\mathrm{ACWP}$

Dengan ketentuan jika:

- $\quad \mathrm{CV}>0$, biaya volume aktual > biaya aktual (cost underrun)

- $\quad \mathrm{CV}<0$, biaya volume aktual < biaya aktual (cost overrun)
Contoh perhitungan Cost Variance (CV) bulan ke 1 adalah sebagai berikut:

Nilai BCWP bulan ke 1=Rp. 594.000.000,Nilai ACWP bulan ke 1 = Rp. 525.000.000,Jadi:

$\mathrm{CV}=\mathrm{BCWP}-\mathrm{ACWP}$

$=$ Rp. $594.000 .000-$ Rp. 525.000 .000

= Rp. 69.000.000

Besarnya CV tiap bulan dapat dilihat dari tabel berikut:

\begin{tabular}{|c|c|c|c|c|}
\hline Bulan ke & BCWP & ACWP & $\mathrm{CV}$ & Keterangan \\
\hline 1 & Rp594,000,000 & Rp525,000,000 & Rp69,000,000 & cost underrun \\
\hline 2 & Rp1,277,100,000 & $\mathrm{Rp} 1,140,000,000$ & Rp137,100,000 & cost underrun \\
\hline 3 & $\mathrm{Rp} 2,019,600,000$ & $\mathrm{Rp} 2,340,900,000$ & -Rp321,300,000 & cost overrun \\
\hline 4 & Rp2,649,240,000 & Rp3,070,000,000 & -Rp420,760,000 & cost overrun \\
\hline 5 & $\mathrm{Rp} 2,851,200,000$ & Rp2,904,800,000 & -Rp53,600,000 & cost overrun \\
\hline 6 & Rp3,166,020,000 & Rp3,000,705,000 & Rp165,315,000 & cost underrun \\
\hline 7 & $\mathrm{Rp} 3,564,000,000$ & $\mathrm{Rp} 4,000,000,000$ & $-\mathrm{Rp} 436,000,000$ & cost overrun \\
\hline 8 & $\mathrm{Rp} 4,098,600,000$ & $\mathrm{Rp} 4,250,650,000$ & -Rp152,050,000 & cost overrun \\
\hline 9 & Rp4,633,200,000 & Rp5,000,300,000 & -Rp367,100,000 & cost overrun \\
\hline 10 & Rp5,049,000,000 & Rp5,852,250,000 & -Rp803,250,000 & cost overrun \\
\hline 11 & Rp5,384,016,000 & Rp6,885,000,000 & -Rp1,500,984,000 & cost overrun \\
\hline
\end{tabular}

Tabel : Cost Variance (CV)

\section{Cost Performance Index (CPI)}

Cost Performance Index (CPI) menggambarkan perbandingan antara nilai hasil (Earned Value) dengan biaya aktual (Actual Cost).

Cost Permance Index $(\mathrm{CPI})=\mathrm{BCWP} /$ ACWP

Dengan ketentuan jika:

- $\quad$ CPI > 1, biaya volume aktual > biaya aktual (cost underrun)
- $\quad$ CPI $<1$, biaya volume aktual < biaya aktual (cost overrun)

Contoh perhitungan CPI bulan ke 1 adalah sebagai berikut:

Nilai BCWP bulan ke 1=Rp. 594.000.000,Nilai ACWP bulan ke $1=$ Rp. 525.000.000,Jadi:

$$
\begin{aligned}
\mathrm{CPI} & =\mathrm{BCWP} / \mathrm{ACWP} \\
& =594.000 .000 / 525.000 .000 \\
& =1.13
\end{aligned}
$$

Besarnya CPI tiap bulan dapat dilihat dari tabel berikut: 
Elvi \& Bambang, analisis kinerja proyek “y”menggunakan metode earned value management...

\begin{tabular}{|c|r|r|r|c|}
\hline Bulan ke & \multicolumn{1}{|c|}{ BCWP } & \multicolumn{1}{|c|}{ ACWP } & CPI & Keterangan \\
\hline 1 & $\mathrm{Rp} 594,000,000$ & $\mathrm{Rp} 525,000,000$ & 1.13 & cost underrun \\
\hline 2 & $\mathrm{Rp} 1,277,100,000$ & $\mathrm{Rp} 1,140,000,000$ & 1.12 & cost underrun \\
\hline 3 & $\mathrm{Rp} 2,019,600,000$ & $\mathrm{Rp} 2,340,900,000$ & 0.86 & cost overrun \\
\hline 4 & $\mathrm{Rp} 2,649,240,000$ & $\mathrm{Rp} 3,070,000,000$ & 0.86 & cost overrun \\
\hline 5 & $\mathrm{Rp} 2,851,200,000$ & $\mathrm{Rp} 2,904,800,000$ & 0.98 & cost overrun \\
\hline 6 & $\mathrm{Rp} 3,166,020,000$ & $\mathrm{Rp} 3,000,705,000$ & 1.06 & cost underrun \\
\hline 7 & $\mathrm{Rp} 3,564,000,000$ & $\mathrm{Rp} 4,000,000,000$ & 0.89 & cost overrun \\
\hline 8 & $\mathrm{Rp} 4,098,600,000$ & $\mathrm{Rp} 4,250,650,000$ & 0.96 & cost overrun \\
\hline 9 & $\mathrm{Rp} 4,633,200,000$ & $\mathrm{Rp} 5,000,300,000$ & 0.93 & cost overrun \\
\hline 10 & $\mathrm{Rp} 5,049,000,000$ & $\mathrm{Rp} 5,852,250,000$ & 0.86 & cost overrun \\
\hline 11 & $\mathrm{Rp} 5,384,016,000$ & $\mathrm{Rp} 6,885,000,000$ & 0.78 & cost overrun \\
\hline
\end{tabular}

Tabel 4 .1 Cost Performance Index (CPI)

\section{Analisa Kinerja Proyek berdasarkan Grafik Kinerja Biaya dan Waktu}

Berikut adalah grafik kinerja biaya dan waktu berdasarkan Budget Cost of Work
Peformance (BCWP), Budget Cost of Work Schedule (BCWS) dan Actual Cost of Work Peformance (ACWP).

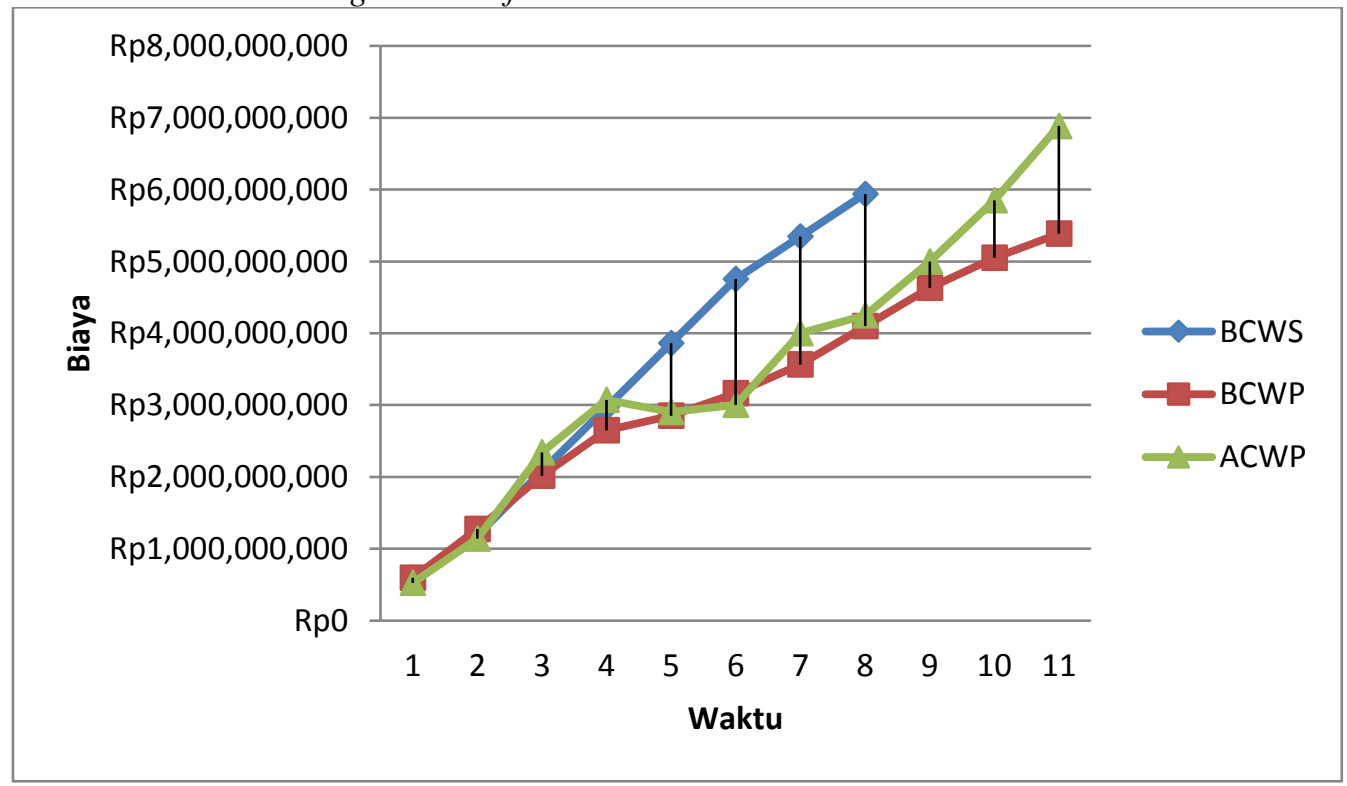

Grafik4 .1 Grafik Kinerja Biaya dan Waktu 
- Analisis bulan ke 1

Pada bulan ke 1 kondisi BCWP $=$ BCWS, menunjukan bahwa proyek stabil tidak mengalami kemajuan atau kemunduran (on schedule). Untuk periode yang sama ACWP < BCWP, menunjukan biaya aktual yang dikeluarkan lebih kecil dari penyelesaian volume pekerjaannya, berarti tidak terjadi penyimpangan biaya (cost underrun). Proyek masih dalam keadaan stabil, dikarenakan masih awal pengerjaan proyek belum melibatkan banyak pihak, jadi pengerjaan proyek masih terkontrol dan terkendali.

- Analisis bulan ke 2

Pada bulan ke 2 kondisi BCWP > BCWS, menunjukan bahwa proyek lebih cepat dari rencana (schedule underrun). Untuk periode yang sama ACWP $<B C W P$, menunjukkan biaya aktual yang dikeluarkan lebih kecil dari penyelesaian volume pekerjaannya, berarti tidak terjadi penyimpangan biaya (cost underrun). Pengerjaan proyek pada bulan ke 2 proyek mengalami peningkatan kinerja.

- Analisis bulan ke 3

Pada bulan ke 3 kondisi BCWP < BCWS, menunjukan bahwa proyek mengalami keterlambatan (schedule overrun). Untuk periode yang sama ACWP>BCWP, menunjukan biaya aktual yang dikeluarkan lebih besar dari penyelesaian volume pekerjaannya, sehingga terjadi penyimpangan biaya (cost overrun). Kinerja proyek mengalami penurunan, dikarenakan terjadi schedule overrun dan cost overrun.Pada bulan ini proyek sudah mulai melibatkan banyak subcontractor dan vendor dikarenakan volume pekerjaan yang semakin meningkat sehingga kurangnya kontrol pada pengerjaan proyek. Menurut observasi di lapangan selain itu juga keterlambatan material juga menjadi salah satu peyebab menurunnya kinerja proyek.

- Analisis bulan ke 4
Pada bulan ke 4 kondisi BCWP < BCWS, menunjukan bahwa proyek mengalami keterlambatan (schedule overrun). Untuk periode yang sama ACWP > BCWP, menunjukan biaya aktual yang dikeluarkan lebih besar dari penyelesaian volume pekerjaannya, sehingga terjadi penyimpangan biaya (cost overrun). Proyek masih mengalami penurunan kinerja. Pengerjaan proyek sudah semakin kompleks, seiring dengan meningkatnya volume pekerjaan proyek juga timbul banyak permasalahan yang mengakibatkan keterlambatan proyek.

- Analisis bulan ke 5 Pada bulan ke 5 kondisi BCWP < BCWS, menunjukan bahwa proyek mengalami keterlambatan (schedule overrun). Untuk periode yang sama ACWP > BCWP, menunjukan biaya aktual yang dikeluarkan lebih besar dari penyelesaian volume pekerjaannya, sehingga terjadi penyimpangan biaya (cost overrun). Pada bulan ke 5 masih terjadi penurunan kinerja proyek.

- Analisis bulan ke 6

Pada bulan ke 6 kondisi BCWP < BCWS, menunjukan bahwa proyek mengalami keterlambatan (schedule overrun). Untuk periode yang sama ACWP < BCWP, menunjukan biaya aktual yang dikeluarkan lebih kecil dari penyelesaian volume pekerjaannya, sehingga tidak terjadi penyimpangan biaya (cost underrun). Pada bulan ke 6 proyek masih mengalami keterlambatan tapi dapat menghemat biaya yang dikeluarkan.Manajemen mengambil tindakan untuk menghemat biaya setelah melihat pengeluaran pada bulan sebelumnya yang overbudget.Tindakan yang dilakukan adalah dengan membatasi jam overtime karyawan, tindakan ini dilakukan berdasarkan pertimbangan tertentu.

- Analisis bulan ke 7

Pada bulan ke 7 kondisi BCWP < BCWS, menunjukan bahwa proyek mengalami keterlambatan (schedule overrun). Untuk 
Elvi \& Bambang, analisis kinerja proyek “y”menggunakan metode earned value management ...

periode yang sama ACWP > BCWP, menunjukan biaya aktual yang dikeluarkan lebih besar dari penyelesaian volume pekerjaannya, sehingga terjadi penyimpangan biaya (cost overrun). Pada bulan ke 7 , proyek kembali mengalami penurunan kinerja. Hal ini dikarenakan client meminta untuk mengubah Project Spesification yaitu berupa revisi drawing yang sudah ada sehingga ada beberapa pekerjaan yang harus diulang.Hal ini tentu berdampak pada waktu dan biaya yang dikeluarkan.

- Analisis bulan ke 8

Pada bulan ke 8 kondisi BCWP < BCWS, menunjukan bahwa proyek mengalami keterlambatan (schedule overrun). Untuk periode yang sama ACWP > BCWP, menunjukan biaya aktual yang dikeluarkan lebih besar dari penyelesaian volume pekerjaannya, sehingga terjadi penyimpangan biaya (cost overrun). Pada bulan ke 8 pengerjaan proyek masih terjadi penurunan kinerja proyek, hal ini terjadi karena dampak dari perubahaan Project Spesification sehingga terjadi keterlambatan dan over budget terus menerus sampai akhir pelaksanaan proyek yaitu pada bulan ke 11 .

Ada banyak sekali penyebab terjadinya keterlambatan pengerjaan proyek untuk setiap proses yang ada di gambar 4.4 dan beberapa faktor lain diantaranya adalah sebagai berikut:

- Material yang tidak sesuai dengan spesifikasi sehingga harus melakukan request ulang dan memakan waktu. Dokumen millcert sering terlambat sehingga material tidak dapat dieksekusi di lapangan.

- Untuk proses fit up harus dilengkapi dengan dokumen dari dimensional control. Proses ini juga membutuhkan waktu yang sedikit lama karena dimensi yang diukur harus dalam batas toleransi. Jika tidak sesuai dilakukan proses fit up ulang.
- Untuk proses welding, masalah yang sering dihadapi adalah masalah repair, barang yang direpair harus dikerjakan ulang sehingga menyebabkan keterlambatan proyek. Selain itu juga faktor cuaca, jika terjadi hujan pengerjaan proyek di lapangan harus dihentikan karena berbahaya dan menyangkut keselamatan kerja.

- Untuk proses NDT permasalahan yang sering terjadi juga masalah repair, material yang dikerjakan tidak memenuhi standar yang ada sehingga harus dikerjakan ulang. Dokumen terkait hasil inspeksi NDT juga sering bermasalah karena sering terjadi miscommunication.

- Fasilitas pengerjaan proyek seperti welding machine, crane, forklift dan fasilitas alat berat lainnya sering bermasalah seperti kurangnya dokumen dan sebagainya.

- Permasalahan dengan aliansi pekerja sehingga menimbulkan demo pekerja dan menyebabkan keterlambatan pekerjaan.

- Permasalahan penyelesaian dokumen, berdasarkan hasil observasi jumlah document control tidak memadai ketika proses pekerjaan sedang meningkat sehingga document tidak selesai tepat waktu.

- Menurut hasil observasi di lapangan, penyebab keterlambatan proyek yang paling berpengaruh terhadapap pengerjaan proyek adalah revisi drawing, proses ini membutuhkan waktu yang lama, mulai dari pergantian spesifikasi, persetujuan dari berbagai pihak yang bertanggung jawab, sampai dengan proses eksekusi. Material yang sudah dikerjakan harus dibongkar dan semua proses harus dikerjakan kembali berdasarkan revisi drawing. 


\section{Perkiraan Biaya dan Waktu Penyelesaian Akhir Proyek}

\section{Estimate to Complete (ETC)}

Estimate to Complete (ETC) merupakan perkiraan biaya untuk pekerjaan yang tersisa. ETC dihitung menggunakan data terakhir pengerjaan proyek yaitu bulan ke 11 .

$\mathrm{ETC}=($ Anggaran $-\mathrm{BCWP}) / \mathrm{CPI}$

Anggaran $\quad=$ Rp. 5.940.000.000,-

BCWP $=$ Rp. 5.384.016.000,-

CPI $=0,78$

$\mathrm{ETC}=(5.940 .000 .000-5.384 .016 .000)$

$/ 0,78$

$=$ Rp. $555.984 .000 / 0,78$

$=$ Rp. 710.984.113,-

Dari perhitungan nilai ETC di atas maka dapat disimpulkan bahwa total perkiraan biaya untuk menyelesaikan sisa pekerjaan proyek sebanyak 9,36\% bobot pekerjaan adalah Rp. 710.984.113,-

\section{Estimate at Completion (EAC)} Estimate at Completion (EAC) merupakan perkiraan total biaya proyek sampai selesai. EAC dihitung menggunakan data terakhir pengerjaan proyek yaitu bulan ke 11.

$$
\begin{aligned}
& \text { EAC }=\text { ACWP }+ \text { ETC } \\
& \begin{aligned}
\text { ACWP } & =\text { Rp. } 6.885 .000 .000,- \\
\text { ETC } & =\text { Rp. } 710.984 .113,- \\
\text { EAC } & =6.885 .000 .000+710.984 .113 \\
& =\text { Rp. } 7.595 .984 .113,-
\end{aligned}
\end{aligned}
$$

Perkiraan total biaya penyelesaian proyek adalah Rp. 7.595.984.113,-. Jika dibandingkan dengan rencana awal anggaran sebanyak Rp. 5.940.000.000,maka selisih total estimasi biaya pada awal proyek dengan estimasi total biaya penyelesaian pengerjaan proyek adalah $\mathrm{Rp}$. 1.655.984.113,-

Selisih perencanaan biaya ini wajar terjadi karena ada perubahan job specification berupa revisi drawing. Perubahan job specification dilakukan berdasarkan permintaan dari client. Untuk proses claim biaya aktual dapat dilakukan berdasarkan progress aktual dari lapangan, sehingga perusahaan tidak mengalami kerugian yang besar walaupun selisih biaya dengan perencanaan awal sangat besar. Walaupun kinerja proyek berdasarkan biaya dinilai rendah, tetapi hal tersebut masih dapat dikurangi karena kekurangan biaya dapat di claim kepada client. Proses pembuatan job specification atau project charter dalam istilah manajemen proyek pada awal pengerjaan proyek sangatlah penting, untuk mengatasi kemungkinan yang akan terjadi sehingga tidak menimbulkan kerugian yang besar. Dalam hal ini perlu dilakukkan analisa terhadap keseluruhan knowledge area dalam manajemen proyek seperti Project Intergration Management, Project Scope Management, Project Time Management, Project Cost Management, Project Quality Management, Project Human Resource Management, Project Communications Management, Project Risk Communication, Project Procurement Management dan Project Stakeholder Management.

\section{Time Estimate (TE)}

Time Estimate (TE ) adalah estimasi waktu penyelesaian proyek sampai selesai. $\mathrm{TE}=\mathrm{ATE}+(\mathrm{OD}-(\mathrm{ATE} \times \mathrm{SPI}))$

$$
\begin{array}{lc}
\text { ATE } & =286 \text { hari } \\
\text { OD } & =208 \text { hari } \\
\text { SPI } & =0,69 \\
\text { TE } & =286+\frac{(208-(286 \times 0.69))}{0,69} \\
& =286+\frac{(208-(197,34)}{0,69} \\
= & 286+\frac{(10.66)}{0,69} \\
& =286+15,45 \\
= & 301,45 / 302 \text { hari }
\end{array}
$$

Jadi perkiraan waktu yang dibutuhkan untuk menyelesaikan proyek adalah selama 302 hari.

Kinerja proyek berdasarkan waktu pengerjaan proyek juga rendah. Hal ini juga disebabkan oleh perubahan job specification berupa revisi drawing dan juga beberapa hal 
Elvi \& Bambang, analisis kinerja proyek “y”menggunakan metode earned value management ...

lain yang menyebabkan keterlambatan proyek. Tentu saja hal ini harus menjadi perhatian manajemen, karena berpengaruh terhadap citra perusahaan, walaupun tidak semua keterlambatan diakibatkan oleh faktor internal perusahaan.Manajemen harus mengambil tindakan untuk mengurangi faktor-faktor yang menjadi penyebab keterlambatan proyek untuk pengerjaan proyek selanjutnya.

Berdasarkan perhitungan Time Estimate di atas dapat diketahui estimasi waktu untuk penyelesaian proyek. Agar proyek dapat dikerjakan sesuai dengan waktu yang diperkiraan maka hal-hal yang menjadi penyebab terjadinya keterlambatan proyek harus diselesaikan. Berdasarkan pembahasan sebelumnya masalah yang paling mempengaruhi terhadap keterlambatan proyek adalah revisi drawing untuk pengerjaan proyek. Agar tidak mempengaruhi untuk penyelesaian pengerjaan proyek, manajemen dan pihak yang terkait harus memastikan tidak ada lagi perubahan setelah pengerjaan proyek lagi nantinya. Departemen produksi, QC dan Engineer harus saling berkoordinasi merencanakan dan membuat revisi drawing, memastikan kembali dengan pihak client apakah drawing yang direvisi sudah sesuai dengan permintaan client atau belum.

Untuk masalah miscommunication yang sering terjadi baik internal maupun dengan eksternal perusahan juga harus diselesaikan. Agar tidak terjadi lagi kesalahpahaman atau miscommunication yang menyebabkan keterlambatan proyek garis koordinasi antar devisi harus ditingkatkan agar komunikasi lebih efektif, penggunaan media komunikasi seperti aplikasi whatssap juga bisa digunakan dengan membuat chat grup yang anggotanya adalah orang-orang yang terlibat dalam pengerjaan proyek sehingga setiap informasi yang dialirkan dapat diketahui semua pihak. Melakukan briefing setiap sebelum mengerjakan pekerjaan supaya pekerja mengetahui apa saja target yang harus diselesaikan setiap harinya.
Mengadakan meeting rutin untuk membahas progress dan masalah-masalah yang terjadi di lapangan.

Pada akhir pengerjaan proyek permasalahan material tidak terlalu menjadi masalah yang besar karena biasanya material sudah tersedia. Permasalahan dengan aliansi pekerjapun tidak terlalu menjadi masalah yang besar karena sudah diselesaikan sebelumnya, tapi tetap harus dijaga komunikasi dan kesepakatan antara aliansi pekerja dengan perusahaan agar tidak terjadi lagi demo.

Pada saat volume pekerjaan meningkat sebaiknya manajemen melakukan penambahan karyawan agar pekerjaan dapat diselesaikan tepat waktu. Karena berdasarkan pembahasan sebelumnya menyebutkan dokumen sering mengalami keterlambatan karena kekurangan sumber daya manusia

Untuk mengatasi masalah repair di lapangan, manajemen harus merekrut karyawan yang memiliki kompetensi untuk pekerjaan tersebut. Selain itu juga bisa meningkatkan kinerja karyawan dengan memberi bonus jika mencapai target pekerjaan sehingga memotivasi karyawan untuk bekerja lebih baik.

\section{Kesimpulan}

Berdasarkan hasil penelitian yang telah dilakukan, maka penulis dapat mengambil kesimpulan sebagai berikut:

1. Waktu aktual pelaksanaan proyek tidak sesuai dengan waktu perencanaan proyek. Proyek mengalami keterlambatan sehingga terjadi penurunan kinerja proyek. Pada bulan ke 1 pelaksanaan proyek tepat waktu, pada bulan ke 2 proyek mengalami keterlambatan (schedule overrun), pada bulan ke 3 terjadi percepatan pada pengerjaan proyek (schedule underrun). Tapi pada bulan selanjutnya sampai akhir pelaksanaan proyek yaitu bulan ke 11, proyek terus mengalami keterlambatan (schedule overrun). Jadi 
berdasarkan waktu pelaksanaan, proyek mengalami penurunan kinerja.

2. Terjadi penyimpangan pada biaya aktual dengan perencanaan proyek. Pada bulan ke 1, 2 dan 6 pengerjaan proyek, biaya aktual yang dikeluarkan lebih sedikit dibandingkan dengan perencanaan biaya (cost underrun). Sisanya mengalami penyimpangan biaya (cost overrun). Jadi berdasarkan biaya pelaksanaan, proyek mengalami penurunan kinerja.

3. Dari perhitungan Estimate to Complete (ETC) maka dapat disimpulkan bahwa perkiraan biaya untuk pekerjaan yang tersisa adalah Rp. 710.980.113,00. Total perkiraan biaya secara keseluruhan dapat dilihat dari perhitungan Estimate at Completion (EAC) yaitu Rp. 7.595.984.113,-

Untuk perkiraan estimasi waktu penyelesaian proyek dapat dilihat dari hasil perhitungan Time Estimate (TE) yaitu selama 302 hari.

\section{Saran}

Berdasarkan penelitian yang telah penulis lakukan, adapun saran yang dapat penulis sampaikan adalah sebagai berikut:

1. Perusahaan perlu melakukan review lebih dalam project specification sebelum memulai proyek agar resiko keterlambatan yang meyebabkan biaya proyek membesar tidak terlalu signifikan.

2. Perlunya perencanaan dan persiapan yang matang untuk pelaksanaan proyek, terutama dalam hal sumber daya.

3. Perlu adanya garis koordinasi yang jelas untuk mengurangi misscomunication baik di internal maupun eksternal perusahaan.

4. Perlu adanya penambahan sumber daya ketika pekerjaan semakin meningkat.

\section{Keterbatasan}

Selama proses penelitian penulis banyak sekali memiliki keterbatasan. Dengan keterbatasan ini diharapkan dapat dilakukan untuk perbaikan yang akan datang. Adapun keterbatasaan-keterbatasan penulis adalah sebagai berikut:

1. Keterbatasan mendapatkan rincian data kemajuan proyek, sehingga penulis tidak bisa menganalisa lebih dalam.

2. Keterbatasan mendapatkan rincian data keuangan, sehingga penulis tidak bisa menganalisa secara lebih rinci data keuangan. Peneliti hanya meneliti biaya secara kesuluruhan saja.

3. Peneliti hanya meneliti pengerjaan modul 301 proyek Yamal Lng bagian structure saja.

4. Keterbatasan waktu penelitian sehingga hasil penelitian kurang maksimal. semoga di penelitian selanjutnya lebih dapat maksimal lagi

\section{DAFTAR PUSTAKA}

Dini, Gusti Rahma., Juliantina, Ika. (2013). Pengendalian Proyek pembangunan Lanjutan SMA Negeri Internasional Sumatera Selatan Palembang dengan Metode Earned Value.Jurnal Teknik Sipil dan Lingkungan. 1 (1), 40-46.

Gupta, Radhika. (2014). Earned Value Management System.International Journal of Emerging Engineering Research and Technology. 4 (2), 160-165.

Husen, Abrar, Ir, MT. (2009). Manajemen Proyek. Yogyakarta: ANDI

Juliana. (2016). Analisis Pengendalian Biaya Dan Waktu Pada Proyek Konstruksi Dengan Metode Earned Value Management (EVM). Jurnal Faktor Exacta.9 (3), 257-265.

Mangkunegara, A.A. Anwar Prabu. (2009).Manajemen Sumber Daya Manusia Perusahaan. Bandung: Remaja Rusdakarya. 
Elvi \& Bambang, analisis kinerja proyek “y”menggunakan metode earned value management ...

Mahsun, Mohamad, SE, M. Si, Ak (2009), Pengukuran Kinerja Sektor Publik. Yogyakarta : $\quad$ BPFEYOGYAKARTA

Pasaribu, Denni Perdinal., Afina, Vera Methalina., Yasra, Refdilzon. (2014). Analisa Pengendalian Proyek Kapal AHTS H 7050 dengan Metode Earned Value (Studi Kasus di PT Batamec Shipyard).Profesiensi. 2 (1), 1-9.

PMBOK Guide.(2013). A Guide to The Project management Body of Knowladge, Fourth Edition. America: Project Management Institute.

Sugiyono, Prof, Dr. (2015). Metode Penelitian Pendidikan: Pendekatan Kuantitatif, Kualitatif, dan $R \& D$. Bandung: Alfabeta.

(2008). Metode Penelitian Kunatitatif Kualitatif dan $R \& D$. Bandung: Alfabeta.

Rivai, Veithzal., Basri, Ahmad Fawzi Mohd.(2005). Performance Appraisal: Sistem Yang Tepat untuk Menilai Kinerja Karyawan dan Meningkatkan Daya Saing Perusahaan. Jakarta: PT Raja Grafindo Persada.

Tika, Pabundu. (2006). Budaya Organisasi Dan Peningkatan Kinerja Perusahaan. Jakarta: PT Bumi Aksara.

Widharto, Sri. (2013). Welding Inspection. Jakarta: Mitra Wacana Media.

Yomelda., Utomo, Christiono. (2015). Analisa Earned Value pada Proyek Pembangunan Viala Hills Villa dan Resort Bogor.Jurnal Teknik ITS. 1 (4), 76-81. 